\title{
III JORNADAS DE FORMACIÓN DOCENTE UNIVERSITARIA: Debates contemporáneos y nuevos escenarios para la formación docente universitaria
}

Silvia Morelli (UNR)*

Organizadas por la Escuela de Ciencias de la Educación, se desarrollaron en la Facultad de Humanidades y Artes de la Universidad Nacional de Rosario, las III Jornadas de Formación docente universitaria: "Debates contemporáneos y nuevos escenarios en la formación docente universitaria" los días 4 y 5 de noviembre de 2010. Por tercera vez consecutiva, se instó a reflexionar sobre la formación docente universitaria. Estuvieron presentes profesores e investigadores de universidades nacionales tales como Universidad Nacional de Misiones, Universidad Nacional del Litoral (Facultad de Bioquímica y Cs Biológicas; Ciencias Humanas), Universidad Nacional de La Pampa (Facultad de Cs Exactas), Universidad Nacional de La Plata (Facultad de Humanidades y Ciencias de la Educación), Universidad Nacional de San Luis, Universidad Nacional de Córdoba, Universidad Nacional de General Sarmiento, Universidad Nacional Patagonia San Juan Bosco, Universidad Nacional de Entre Ríos (Facultad de Ingeniería). De nuestra Universidad participaron, además de la Secretaría de Extensión Universitaria, las Facultades de Odontología, Ciencias Veterinarias, Humanidades y Artes, Ciencias Exactas, Ingeniería y Agrimensura, Ciencias Agrarias, Ciencias Médicas y Arquitectura, Planeamiento y Diseño.

Asistentes, expositores, panelistas y conferencistas se dieron lugar en torno a temas como la importancia de los escenarios de las prácticas para la formación, las didácticas específicas y la construcción de contenidos en la educación universitaria, las problemáticas curriculares que actualmente involucran a la educación superior y a la formación docente, la importancia adquirida y el escaso debate que todavía presentan las tecnologías de la comunicación en la formación docente, la necesidad de redefinición de políticas universitarias

Magister en Ciencias de la Comunicación. Prof. en Ciencias de la Educación, Directora de la Escuela de Ciencias de la Educación, Fac. Humanidades y Artes, UNR. 
acordes con las demandas sociales y el desarrollo de la investigación educativa como un problema cuya historia sigue construyéndose en torno a la formación docente universitaria, no por ello menos importante que problemáticas de reciente tratamiento. Es precisamente porque constituye un campo ya tratado por los actores universitarios y atendiendo a la abundancia de investigaciones desarrolladas, se decidió éste como eje para la presentación de pósters.

Un tema central vertebra el estado de situación, finalizando esta década. La inclusión de la formación docente universitaria como profesión regulada por el estado y su controversial evaluación y acreditación. Los espacios dedicados a este tema provocaron el interés de los participantes y permitieron la organización de paneles como "Políticas universitarias para la formación docente", "Debates sobre la acreditación de los profesorados", "Políticas de articulación en la Formación Docente: la Secretaría de Políticas Universitarias y el Instituto Nacional de Formación Docente". Ayudados por especialistas en la materia, directoras de profesorados universitarios de la UNR e integrantes de proyectos ministeriales, este trayecto temático permitió socializar un problema tan relevante como es el de la acreditación de una carrera universitaria.

Las dos conferencias ponen el acento a temas de vital y permanente importancia para la formación docente universitaria. Una, a cargo de Flavia Terigi, destinada a reflexionar sobre la formación docente para la escuela secundaria, en momentos en los que el sistema educativo argentino se viene preparando para dar cabida a la inclusión de jóvenes en la educación obligatoria y la segunda, a cargo de Estanislao Antelo que proporciona una reflexión sobre el oficio y el arte del docente.

\section{Un lugar para los libros}

Las III Jornadas de Formación Docente Universitaria tuvieron la particularidad de hacer lugar a presencia material de los libros. Fiel a su tradición, se dio lugar a la presentación del libro "La práctica docente universitaria en educación a distancia. Procesos metacognitivos y buena enseñanza" de Susana Copertari (UNR). Laborde Editor. La misma estuvo a cargo de la Dra. María Isabel Pozzo (UNR/CONICET); la Mg. Carina Pacini (UTN Regional San Nicolás. Pcia. de Bs. As) y la Mg. Silvia Morelli (Directora de la Escuela de Ciencias de la Educación. FHyA. UNR). En este libro la Magister Copertari, relata una investigación realizada sobre las experiencias de educación a distancia universitarias. La exhaustividad del aporte teórico se funde con el abundante material empírico que presenta y las recomendaciones para la elaboración de políticas en este tema.

Otro acontecimiento fue la inauguración de la Biblioteca "Prof. Mario López Dabat". Donada por la familia del profesor, esta biblioteca cuya catalogación fue realizada por las profesoras de esta escuela expertas en el tema, cuenta con 965 libros que recorren la historia de la educación del siglo XX: la reforma 
universitaria, la formación de la maestra normal nacional, la escuela nueva y el conductismo, entre otros.

Estas Jornadas continuaron confirmando que la formación docente universitaria es un objeto de debate, investigación y construcción de políticas que destaca a las universidades nacionales y ubica a los sujetos universitarios como protagonistas en la construcción de la relación entre la universidad y la sociedad. 